\title{
Reduced graphene oxide-bismuth oxide composite as electrode material for supercapacitors
}

\author{
Mateusz Ciszewski • Andrzej Mianowski • \\ Piotr Szatkowski • Ginter Nawrat • Jakub Adamek
}

Received: 24 February 2014 /Revised: 25 May 2014 / Accepted: 9 June 2014 /Published online: 20 June 2014

(C) The Author(s) 2014. This article is published with open access at Springerlink.com

\begin{abstract}
We have reported a new reduced graphene oxidebismuth oxide composite that can be used as a supercapacitor electrode. $\mathrm{Bi}_{2} \mathrm{O}_{3}$ was synthesized from bismuth nitrate pentahydrate and oxalic acid as a precipitating agent using a hydrothermal process in an aqueous graphene oxide suspension. Instead of mixing graphene oxide with bismuth oxide, we have developed a bismuth oxalate precipitation between the layers. As prepared, composite of hydrated bismuth oxalate and graphene oxide was converted to bismuth oxide and reduced graphene oxide by thermal decomposition in a muffle stove. The material exhibited the specific capacitance of $94 \mathrm{~F} /$ $\mathrm{g}$ at current density $0.2 \mathrm{~A} / \mathrm{g}$. Using the cyclic voltammetry, the specific capacitance was as high as $55 \mathrm{~F} / \mathrm{g}$ at scan rate $5 \mathrm{mV} / \mathrm{s}$ over the potential range $0-1 \mathrm{~V}$. The material exhibited longterm cycle stability retaining $90 \%$ specific capacitance after 3,000 cycles. Except $\mathrm{Bi}^{3+}$ ions present in $\mathrm{Bi}_{2} \mathrm{O}_{3}$, some amount of higher energy $\mathrm{Bi}^{5+}$ was confirmed.
\end{abstract}

Keywords Graphene oxide · Bismuth oxide ·

Supercapacitors $\cdot$ Thermal treatment

M. Ciszewski $(\bowtie) \cdot A$. Mianowski $\cdot$ G. Nawrat

Faculty of Chemistry, Department of Inorganic, Analytical

Chemistry and Electrochemistry, Silesian University of Technology,

Krzywoustego 6, 44-100 Gliwice, Poland

e-mail: mateusz.ciszewski@polsl.pl

P. Szatkowski

Faculty of Materials Science and Ceramics, Department of Biomaterials, AGH University of Science and Technology,

Mickiewicza 30, 30-059 Krakow, Poland

J. Adamek

Faculty of Chemistry, Department of Organic Chemistry, Biochemistry and Biotechnology, Silesian University of Technology, Krzywoustego 4, 44-100 Gliwice, Poland

\section{Introduction}

Electrochemical supercapacitors are the promising energy storage materials that due to long cycle life and high-power density may be applied in many areas of everyday living, i.e., back-up memories, traffic warning signals, engine starting and acceleration, and load lifting. They briefly store electric energy in an electrochemical double layer, so-called Helmholtz layer, forming the solid-electrolyte interface. As their capacitance is proportional to the surface area of the electrode material, highly porous, chemically and electrochemically inert carbons are considered as good candidates for supercapacitor matrices. The higher specific surface area, the higher charge contact interface; however, an increase in capacitance may be also obtained by intercalation of an active species like conducting polymers, metal nanoparticles, and metal oxides. Composite materials containing metal oxide are generally classified as conversion electrodes [1], where capacitance arises from typical charge separation and pseudocapacitance caused by Faradaic reactions [2]. Redox reactions between electrolyte and metal oxide can significantly increase the specific capacitance. Within many proposals of metal oxide-carbon composites, transition metal oxides are privileged; however, silicon and tin chemistry is also well developed. In this paper, we report a reduced graphene oxide-bismuth oxide composite produced by intercalation of graphene oxide suspension with bismuth nitrate and subsequent precipitation of bismuth salt using oxalic acid as a precipitating agent. In the second step as prepared, composite is thermally treated to reduce graphene oxide and convert bismuth oxalate into bismuth oxide. Recently, the interest in poor metals and metalloids in energy storage devices is growing up. Among them, bismuth seems to be a good candidate because of nontoxic character in comparison to the neighbors from the periodic table, namely, lead and antimony [3]. Generally, bismuth chemistry is mainly focused on medical and catalytic applications. In medicine, bismuth compounds are most commonly used for 
treating gastrointestinal disorders [4] while in organic synthesis may be applied in Friedel-Crafts acylation, Michael reactions, synthesis of lactones, and oxidation of thiols [3]. Bismuth is a relatively inexpensive material, in comparison to most extensively studied ruthenium [5], and can be obtained as a byproduct in copper, lead, and tin mining. The electrical conductivity of bismuth oxide is E-3 S/cm and is much higher than for $\mathrm{MnO}_{2}$, which is considered as an attractive alternative to ruthenium oxide [6, 7]. Commercially, bismuth oxide can be obtained using one of the three methods [8]: dissolution of bismuth in nitric acid and subsequent calcinations of bismuth nitrate, reaction of bismuth nitrate with alkali-metal hydroxide, and direct oxidation of bismuth at $850-900{ }^{\circ} \mathrm{C}$. In laboratory scale, $\mathrm{Bi}_{2} \mathrm{O}_{3}$ can be synthesized from bismuth nitrate and urea with thermal decomposition of the solid product [9], hydrothermal synthesis [10], and thermal decomposition of bismuth oxalate [11, 12]. Among five polymorphic forms of bismuth oxide, $\alpha-\mathrm{Bi}_{2} \mathrm{O}_{3}, \beta-\mathrm{Bi}_{2} \mathrm{O}_{3}, \gamma-\mathrm{Bi}_{2} \mathrm{O}_{3}, \delta-\mathrm{Bi}_{2} \mathrm{O}_{3}$, and $\omega-\mathrm{Bi}_{2} \mathrm{O}_{3}$, only $\alpha$-and $\delta$-are thermodynamically stable while $\beta$-and $\gamma$ - are metastable, and depending on the method of synthesis, the specific surface area of $\mathrm{Bi}_{2} \mathrm{O}_{3}$ may vary from 0.2 to $39 \mathrm{~m}^{2} / \mathrm{g}$ [13-15]. $\beta-\mathrm{Bi}_{2} \mathrm{O}_{3}$ can be synthesized from an amorphous substrate by thermal treatment in a very narrow temperature range around $380-385^{\circ} \mathrm{C}$; at higher annealing temperature, $\beta-\mathrm{Bi}_{2} \mathrm{O}_{3}$ is transformed to the thermodynamically stable $\alpha$ phase [16]. Synthesis of bismuth oxide requires an appropriately high $\mathrm{pH}$ value to ensure low amounts of $\mathrm{OH}$ groups in bismuth hydroxo oxide and/or decomposition temperature above $300{ }^{\circ} \mathrm{C}$ to convert this bismuth hydroxo oxide into final bismuth oxide. Instead of this, we have performed reaction at low $\mathrm{pH}$ with the oxalic acid as a precipitating agent, to fully hydrolyze bismuth salt and allow to penetrate interlayer spaces. One should remember that around $400^{\circ} \mathrm{C}$ in air removal of graphene from the composite occurs [17]; therefore, we have thermally converted bismuth species at temperature $380^{\circ} \mathrm{C}$. To the best of our knowledge, graphene-bismuth oxide composites were successfully synthesized using solvothermal synthesis in autoclave and further calcination [17] and thermal treatment of bismuth oxalate [18]. As graphene oxide is easily penetrated by water due to the oxygen-containing groups and bismuth oxide is water insoluble, we have used modified nitrate-oxalate process where graphene oxide suspension was at first mixed with bismuth nitrate and then bismuth oxalate was precipitated in the whole volume of graphene oxide suspension.

\section{Experimental}

Preparation of bismuth composites

Graphite oxide (GO) was synthesized by a modified Staudenmaier's method [19] from the synthetic graphite (SGL Company) and oxidation time was $330 \mathrm{~h}$. Next,
$300 \mathrm{mg}$ GO was ultrasonicated in $200 \mathrm{ml}$ water to produce graphene oxide suspension. Simultaneously, two solutions were prepared, one containing $1.21 \mathrm{~g} \mathrm{Bi}\left(\mathrm{NO}_{3}\right)_{3} \cdot 5 \mathrm{H}_{2} \mathrm{O}$ in $50 \mathrm{ml}$ deionized water with $1 \mathrm{ml} 65 \% \mathrm{HNO}_{3}$ and second $0.9 \mathrm{~g} \mathrm{H}_{2} \mathrm{C}_{2} \mathrm{O}_{4} \cdot 2 \mathrm{H}_{2} \mathrm{O}$ in $50 \mathrm{ml}$ water. Both of them were heated on a hot plate up to $90{ }^{\circ} \mathrm{C}$. Then, bismuth solution was added to graphene oxide and reaction mixture was magnetically mixed at $500 \mathrm{rpm}$. After that, the solution containing the precipitating agent was added and mixing was continued for $6 \mathrm{~h}$. Then, it was boiled at $100{ }^{\circ} \mathrm{C}$ for $1 \mathrm{~h}$, diluted with deionized water, filtrated on a fritted-glass funnel using a filter paper with narrow pores (Munktel, Grade 390), and washed with 1.51 of water. Product was dried at $110^{\circ} \mathrm{C}$ in an oven for $1 \mathrm{~h}$. Finally, graphene oxide-bismuth oxalate composite was reduced and converted to bismuth oxide by thermal decomposition at $380^{\circ} \mathrm{C}$ in a muffle stove resulting in a composite of reduced graphene oxide and bismuth oxide. The composite was labeled as $\mathrm{BiOX}$.

\section{Characterization}

Materials were characterized with powder X-ray diffraction (X'Pert Pro, Philips) with a step size $0.02^{\circ}$ and $\mathrm{Cu} \mathrm{K} \alpha$ radiation to evaluate reduction progress and identify bismuth species. The IR spectra were measured on a Nicolet 6700 FTIR spectrophotometer with attenuated total reflectance (ATR method). The morphology of the products was characterized by scanning electron microscopy with energy-dispersive Xray spectroscopy (SEM with EDS, NOVA NANO SEM 200, Fei Europe Company). The chemical composition of the material was determined by X-ray photoelectron spectroscopy (XPS) using a monochromatic X-ray beam source at $1,486 \mathrm{eV}$ (aluminum anode) (PHI 5700, Physical Electronics).

\section{Electrochemical measurements}

All electrochemical experiments were performed with Autolab PGSTAT 30 workstation using the two-electrode symmetric system. The working electrode and counter/ reference electrode, composed of $15 \mathrm{mg}$ of active material and $2.5 \mathrm{mg}$ PTFE binder (Sigma Aldrich, $35 \mu \mathrm{m}$ ), were pasted on two electrochemical nickel current collectors. Electrodes were separated with PTFE membrane (Whatman, 90- $\mu \mathrm{m}$ thickness) soaked with $6 \mathrm{M} \mathrm{KOH}$. The weight of the electrodes was accurately determined by a high-precision balance (Mettler Toledo AT 261 DeltaRange). The cells were tested by the cyclic voltammetry (CV) at scan rates 1, 5, 20, and $500 \mathrm{mV} / \mathrm{s}$, galvanostatic charge/discharge, and electrochemical impedance spectroscopy (EIS) in frequency range from $100 \mathrm{kHz}$ to $100 \mathrm{mHz}$. The impedance measurements were performed at an open-circuit voltage with a $10-\mathrm{mV}$ voltage amplitude. The specific capacitance values were obtained from the galvanostatic charge/discharge curves using $\mathrm{C}_{\mathrm{sp}}=i t$ / 
( $m \mathrm{~d} U$ ), where $i$ is the current, $t$ is the discharge time, $m$ is the mass of active material of the one electrode, and $\mathrm{d} U$ is the range of voltage. Capacitance was also obtained from the $\mathrm{CV}$ curves using the following formula: $C=\frac{1}{\left(E_{2}-E_{1}\right) v} \int_{E 1}^{E 2} I(E) d E$, while specific capacitance using $\mathrm{C}_{\mathrm{sp}}=2 \mathrm{C} / \mathrm{m}$, where $\mathrm{E}_{1}, \mathrm{E}_{2}, v$, and $\mathrm{m}$ are the initial potential, final potential, scan rate, and mass of the active material of one electrode, respectively.

\section{Results}

We have based on a previously reported method [11, 18] using oxalic acid and bismuth nitrate; however, we have modified the order and manner of reagent addition. This formed composite of graphene oxide with bismuth oxalate that was further converted by thermal treatment into reduced graphene oxidebismuth oxide composite. The as-prepared composite is a greenish-yellow fluffy powder. The presence of yellowcolored domains initially satisfied conversion of bismuth oxalate into bismuth oxide. The precise characterization of a bismuth compound synthesized within reduced graphene oxide and reduction progress of thermally treated graphene oxide were analyzed by XRD.

Figure 1 presents the X-ray diffraction patterns of GO and the reduced graphene oxide-bismuth oxide composite. It can be found that oxidized form of graphite (green) possesses a characteristic signal located near $12^{\circ}$ corresponding to the interlayer distance $d_{002}$ of $0.72 \mathrm{~nm}$. This signal satisfies the presence of corrugated locally parallel layers with much lower crystallinity than observed in graphite (much smaller height of crystallites, $L_{\mathrm{c}}$ calculated from the Scherrer formula). The absence of the graphitic signal usually located at $26^{\circ}$ satisfies total oxidation of graphite. The thermally treated composite of graphene oxide with bismuth salt (red) has well-developed signals that were assigned to $\beta-\mathrm{Bi}_{2} \mathrm{O}_{3}$ (Card No. 01-0775341) and $\mathrm{Bi}_{2}\left(\mathrm{CO}_{3}\right) \mathrm{O}_{2}$ (Card No. 00-025-1464). The oxycarbonate phase is generally converted to $\beta-\mathrm{Bi}_{2} \mathrm{O}_{3}$ at temperature range $260-400{ }^{\circ} \mathrm{C}$ [20]. The $\mathrm{BiOX}$ pattern possesses low-intensity reduced graphene oxide signal at $24^{\circ}$ satisfying presence of few-layer graphene domains; no signal belonging to $\mathrm{GO}$ was observed that evidenced the entire GO reduction.

Qualitative analysis of GO and BiOX was performed using infrared spectroscopy. Figure 2 shows FTIR spectra recorded for both analyzed samples. GO spectrum showed a broad signal located at $3,700-2,800 / \mathrm{cm}$ attributed to the stretching vibration in hydroxyl groups and water molecules as well as signal at 1,715/cm belonging to the carboxylic groups, 1,614/ $\mathrm{cm}$ to $\mathrm{OH}$ groups, $1,347 / \mathrm{cm}$ due to deformation vibration in $\mathrm{C}-\mathrm{OH}, 1,042 / \mathrm{cm}$ represented by $\mathrm{C}-\mathrm{O}$ groups sometimes designated to C-O-C groups [21], and finally peak around 966/cm that may be assigned to the epoxy groups. In the BiOX, most of signals from the oxygen-containing groups become very weak or vanished as a result of thermal treatment; however, two small signals located at 1,383 and $845 / \mathrm{cm}$ appeared. Although it is relatively hard to identify signals below 900/ $\mathrm{cm}$, we suppose that both of them may be assigned to some combination of bismuth oxide with the oxygen-containing groups in reduced graphene oxide not desorbed during thermal treatment, possibly bismuth oxide carbonate [22].

SEM images of the GO and BiOX (Fig. 3) show morphology of the matrix material before compositing and the presence of bismuth particles in the composite, respectively. Figure 3 a presents a GO structure with corrugated layers and rose-like particles while Fig. 3b shows more size-uniformed reduced graphene oxide matrix with randomly distributed, irregular size bismuth oxide particles. The size of bismuth oxide particles varies from a few micrometers to $150 \mu \mathrm{m}$.

The composition of $\mathrm{GO}$ and $\mathrm{BiOX}$ particles was adjusted at higher magnifications $(\times 5,000)$ using EDS. Figure $3 c, d$ shows GO particle and bismuth oxide domains analyzed by EDS, and Fig. 3e, f show EDS results for $\mathrm{GO}$ and $\mathrm{BiOX}$, respectively. Base on EDS results and [23] it can be noticed that GO possesses quite high amount of oxygen and some amount of sulfur residue from the graphite oxidation process. Analysis of bismuth oxide domains shows relatively high amount of bismuth, oxygen, and carbon that satisfies the presence of bismuth oxide deposited on the reduced graphene oxide. Interestingly, bismuth signal was much stronger for domain denoted on a SEM image with 2 than for 1 and 3. This domain (2) magnified $\times 10,000$ and $\times 20,000$ revealed agglomerated rod-like particles. It shows that using this synthesis method, bismuth oxide particles may have various shape and size from small rods up to big platelets. This allows better penetration of graphene oxide matrix, more uniform distribution of active species in electrode material and enhances the specific capacitance.

XPS measurements were carried out to determine elemental composition and chemical structure of BiOX. The $\mathrm{C} 1 \mathrm{~s}$ spectra is shown in Fig. $4 \mathrm{a}$ and four different peaks centered at $283.89,285.28,286.63$, and $289.93 \mathrm{eV}$ can be attributed to the $\mathrm{sp}^{2} \mathrm{C}, \mathrm{sp}^{3} \mathrm{C}, \mathrm{C}-\mathrm{O}$, and $\mathrm{C}=\mathrm{O}$ group, respectively. The percentage of $\mathrm{C}-\mathrm{O}$ and $\mathrm{C}=\mathrm{O}$ is 17.8 and $11.3 \%$, respectively, indicating large amounts of the oxygen functionalities after thermal treatment at temperature as low as $380{ }^{\circ} \mathrm{C}$. Figure $4 \mathrm{~b}$ presents $\mathrm{Bi} 4 \mathrm{f}$ spectra with four different peaks centered at a 158.76, 160.76, 164.07, and $166.07 \mathrm{eV}$ that can be attributed to $\mathrm{Bi}_{2} \mathrm{O}_{3}, \mathrm{Bi}^{\mathrm{V}}, \mathrm{Bi}_{2} \mathrm{O}_{3}$, and $\mathrm{Bi}^{\mathrm{V}}$, respectively. The signal of $\mathrm{Bi}_{2} \mathrm{O}_{3}$ matches perfectly with the literature while signals with higher bond energies can be attributed to bismuth on the fifth oxidation state. To ensure that $\mathrm{Bi}^{\mathrm{V}}$ is really present, sample was evacuated in an ultra-high vacuum for 4 days and analysis was repeated. The amount of higher energy Bi states was diminished but still present in a sample. The percentage of 
Fig. 1 XRD patterns of the parent $\mathrm{GO}$ (green) and $\mathrm{BiOX}$ composite (red)

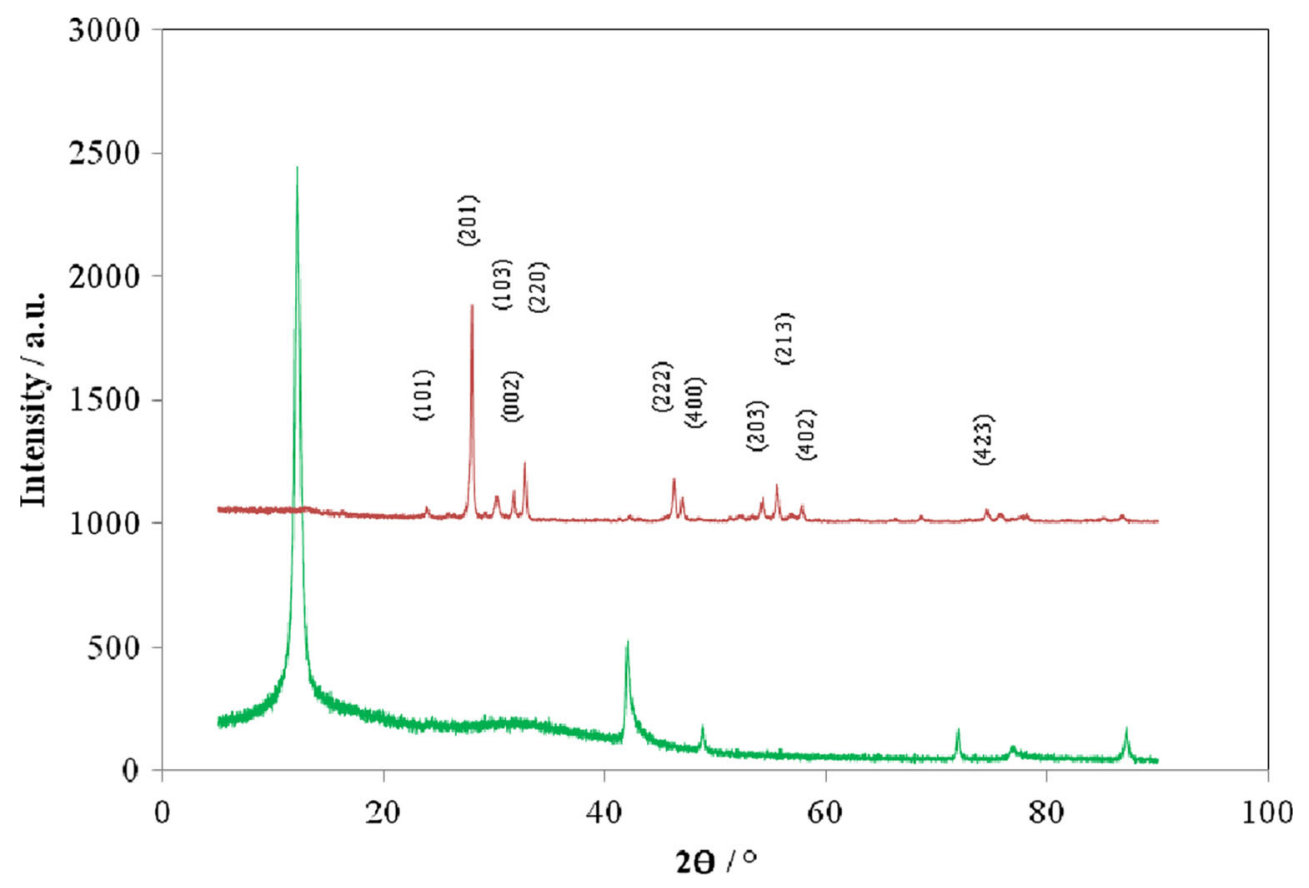

$\mathrm{Bi}_{2} \mathrm{O}_{3}$ was $46 \%$ while $\mathrm{Bi}^{\mathrm{V}} 54 \%$. The total amount of bismuth, oxygen, and carbon in the $\mathrm{BiOX}$ composite was 5 , 18 , and $77 \%$, respectively.

$\mathrm{BiOX}$ electrodes were electrochemically characterized in the two-electrode cell by the galvanostatic charge/discharge, cyclic voltammetry, and electrochemical impedance spectroscopy. Experiments were performed at scan rates 1, 5, 20, and $500 \mathrm{mV} / \mathrm{s}$ in a potential window from 0 to $1 \mathrm{~V}$, which is the most suitable for aqueous electrolyte-based supercapacitors [24]. In this potential window, both graphene matrix and bismuth oxide are stable that is evidenced by a box-like shape of the $\mathrm{CV}$ profiles. Figure 5a shows $\mathrm{CV}$ curves obtained at 1 and $5 \mathrm{mV} / \mathrm{s}$ while Fig. $5 \mathrm{~b}$ at 20 and $500 \mathrm{mV} / \mathrm{s}$, respectively. The slight peak located near $1 \mathrm{~V}$ (Fig. 5a) is most probably caused by a low-hydrogen overvoltage of bismuth in this region [25]. The specific capacitance from CV curves was as high as $55 \mathrm{~F} / \mathrm{g}$ at $5 \mathrm{mV} / \mathrm{s}$. CV curves of BiOX show good cycling stability over 3,000 cycles at scan rate $500 \mathrm{mV} / \mathrm{s}$ (Fig. 5b) with $10 \%$ decrease in the specific capacitance. Generally, the CV curves show good reversible charge/discharge characteristics of the composite electrode and combination of double-layer capacitance with pseudocapacitance that partially results from a good electrical conductivity of randomly distributed $\beta-\mathrm{Bi}_{2} \mathrm{O}_{3}$ that is between $\alpha$ - and $\delta$-phase [26].

The galvanostatic charge/discharge is the most credible method to calculate the specific capacitance. It is used to show
Fig. 2 FTIR-ATR spectra of the $\mathrm{GO}$ (green) and reduced graphene oxide-bismuth oxide composite (red)

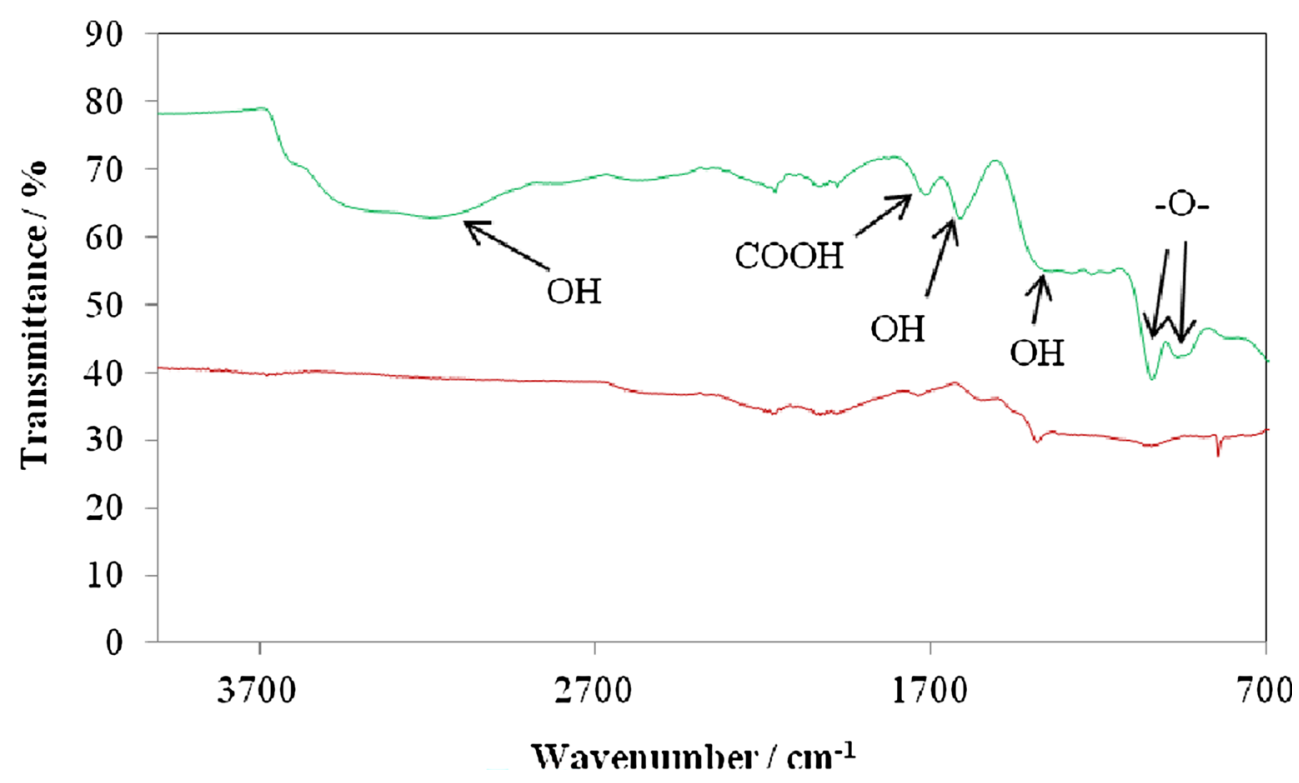


Fig. 3 SEM images. a, b GO and $\mathrm{BiOX}$ at $\times 1,000$ magnification. $\mathbf{c}$, d $\mathrm{GO}$ and $\mathrm{BiOX}$ at $\times 5,000$ magnification with denoted domains analyzed by EDS. e, $\mathbf{f}$ EDS spectra of GO and $\mathrm{BiOX}$, respectively. $\mathbf{g}, \mathbf{h} \mathrm{BiOX}$ domain with agglomerated rod-like bismuth oxide particles at magnification $\times 10,000$ and $\times$ 20,000
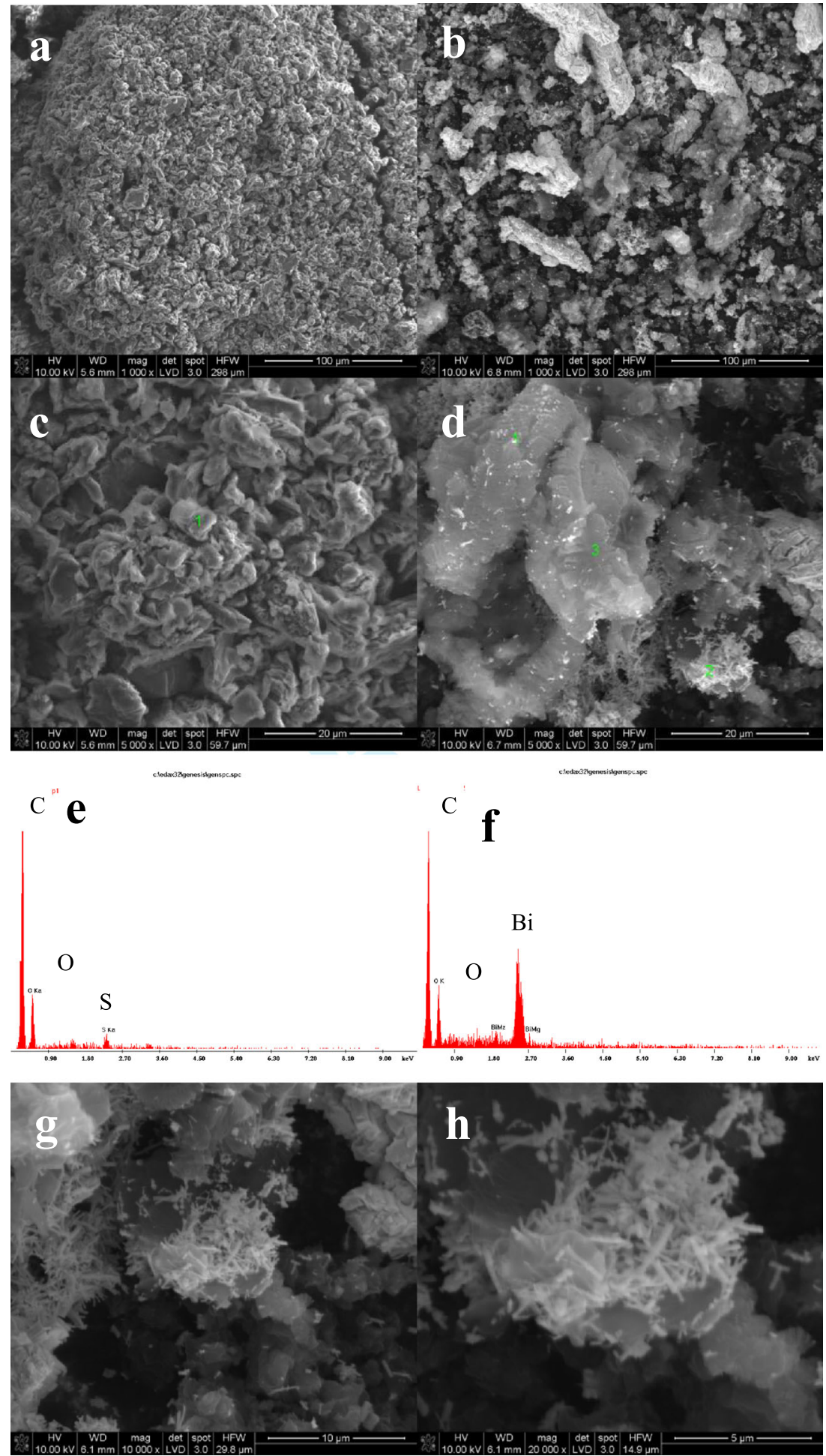

real capacitance value and charge/discharge characteristics of energy-storing materials. Figure 6 a shows the galvanostatic charge/discharge curves obtained for $\mathrm{BiOX}$ at current density from 0.1 to $0.2 \mathrm{~A} / \mathrm{g}$ and various discharge time. The specific capacitance was as high as $94 \mathrm{~F} / \mathrm{g}$ at current density $0.2 \mathrm{~A} / \mathrm{g}$ that is much more than obtained for parent $\mathrm{GO}$
(4.4 F/g). The material can be discharged almost completely and works practically in whole range of potential window. The very steep almost vertical first part of discharge curve indicates probably internal resistance of the material while linear dependence and slope variation in the next stage is attributed to the double- 
Fig. 4 XPS C 1 s spectra (a) and Bi $4 \mathrm{f}$ spectra (b) of reduced graphene oxide-bismuth oxide composite
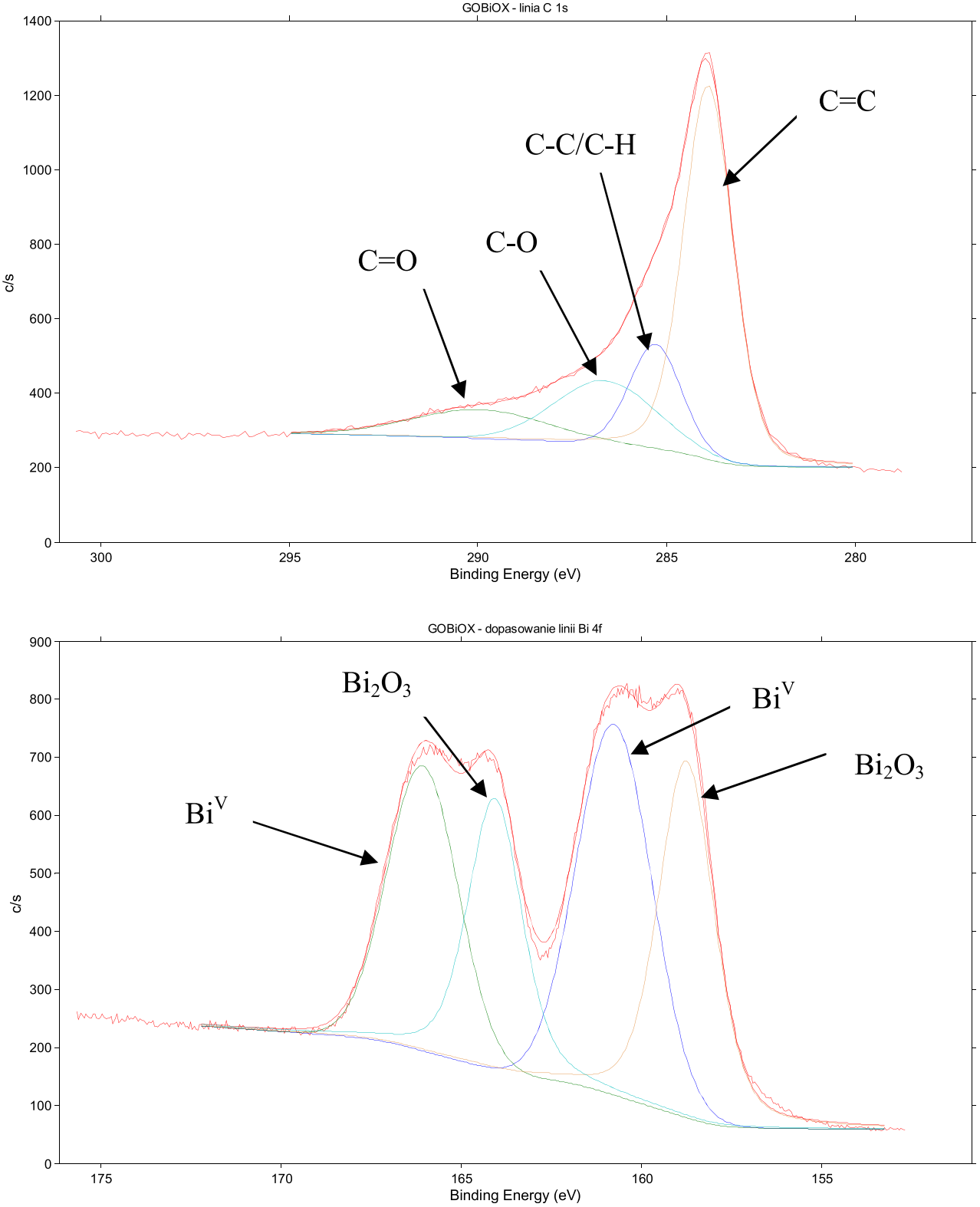

layer separation and pseudocapacitance effects resulted from redox reactions [27].

Fig. 5 Cyclic voltammograms of BiOX at scan rate: $1 \mathrm{mV} / \mathrm{s}$ (blue) and $5 \mathrm{mV} / \mathrm{s}(\mathrm{red})(\mathbf{a})$ and $20 \mathrm{mV} / \mathrm{s}$ (blue) and $500 \mathrm{mV} / \mathrm{s}$ (red) (b)
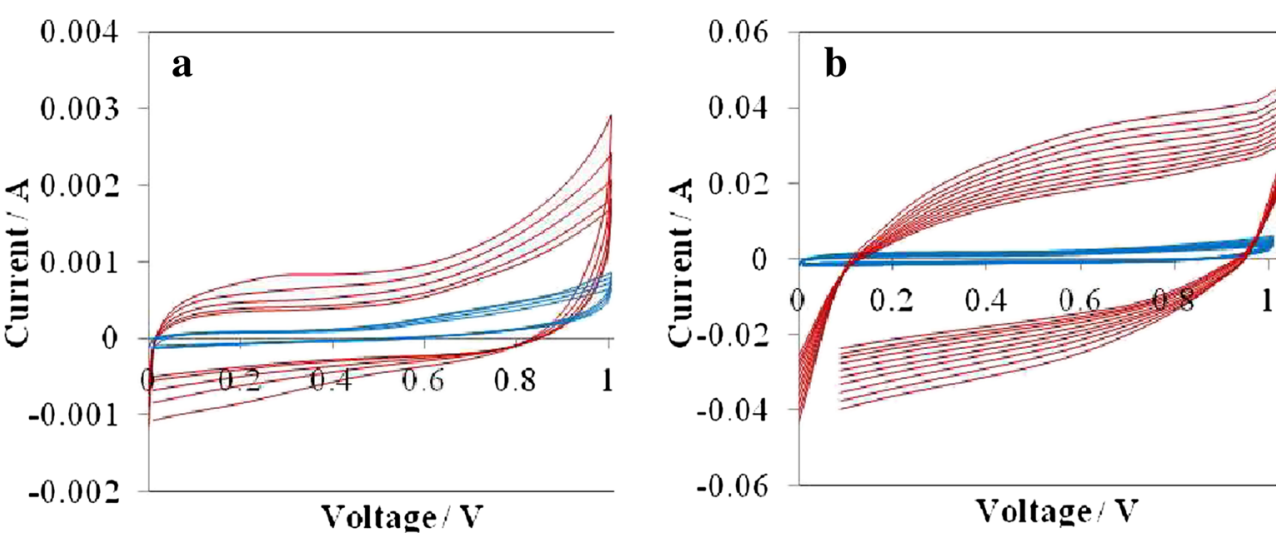
Fig. 6 a Galvanostatic charge/ discharge curves of $\mathrm{BiOX}$ at current density: $0.14 \mathrm{~A} / \mathrm{g}(a), 0.13$ $\mathrm{A} / \mathrm{g}(b), 0.1 \mathrm{~A} / \mathrm{g}(c)$, and $0.2 \mathrm{~A} / \mathrm{g}$ (d) and $\mathbf{b}$ Nyquist plots of GO (green) and $\mathrm{BiOX}$ composite (red)

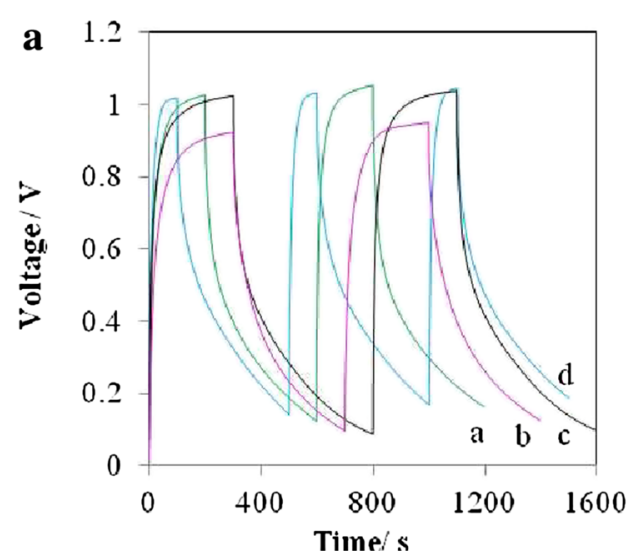

the impedance measured at an equilibrium open-circuit potential $(0 \mathrm{~V})$ in the frequency range from $100 \mathrm{kHz}$ to $100 \mathrm{mHz}$ for BiOX and parent GO. The BiOX electrode exhibit a semicircle over the high-frequency region corresponding to the Faradaic charge transfer resistance [28] and linear part in a low-frequency range indicating a pure capacitive behavior and representing the ion diffusion in the electrode structure. Steeper curve in the low-frequency region of BiOX is attributed to the better Warburg diffusion caused by an improved effective mass transfer from the electrolyte to the electrode interface in the composite. Lack of the semicircle and $45^{\circ}$ degree line for GO indicates very poor conductivity and slow electrode reactions. High capacitance of BiOX arises from higher electric conductivity of reduced graphene oxide and bismuth oxide $[29,30]$ in comparison to parent $\mathrm{GO}$ containing the oxygen groups, larger specific surface area, and pseudocapacitance caused by intercalated bismuth oxide particles.

\section{Conclusions}

The reduced graphene oxide-bismuth oxide composite has been successfully synthesized using simple mixing of bismuth salt with graphene oxide suspension in water at low $\mathrm{pH}$ and thermal treatment in air. This composite possesses randomly distributed rod-like and platelet tetragonal $\beta-\mathrm{Bi}_{2} \mathrm{O}_{3}$ particles embedded in effectively reduced graphene oxide. The presence of high-energy $\mathrm{Bi}^{\mathrm{V}}$ in the bismuth phase was confirmed. Reduced graphene oxide-bismuth oxide composite showed the enhanced specific capacitance, as high as $94 \mathrm{~F} / \mathrm{g}$ and good stability, resulting from the pseudocapacitance of bismuth oxide, its enhanced electrical conductivity and large area of charge separation in reduced graphene oxide matrix.

Open Access This article is distributed under the terms of the Creative Commons Attribution License which permits any use, distribution, and reproduction in any medium, provided the original author(s) and the source are credited.

\section{References}

1. Nitta N, Yushin G (2013) Part Part Syst Charact 1-20

2. Buglione L, Chng ELK, Ambrosi A, Sofer Z, Pumera M (2012) Electrochem Commun 14:5-8

3. Bothwell JM, Krabbe SW, Mohan RS (2011) Chem Soc Rev 40: 4649-4707

4. Briand GG, Burford N (1999) Chem Rev 99:2601-2658

5. Patake VD, Lokhande CD, Joo OS (2009) Appl Surf Sci 255:4192-4196

6. Takahashi T, Iwahara H, Nagai Y (1972) J Appl Electrochem 2:97-104

7. Bélanger D, Brousse T, Long JW (2008) Interface 17:49-52

8. Kelly Z, Ojebuoboh F (2002) JOM 54:42-45

9. Jha RK, Pasricha R, Ravi V (2005) Ceram Int 31:495-497

10. Lu H, Wang S, Zhao L, Dong B, Xu Z, Li J (2012) RSC Adv 2:3374 3378

11. Muruganandham M, Amutha R, Lee GJ, Hsieh SH, Wu JJ, Sillanpää M (2012) J Phys Chem C 116:12906-12915

12. Bahmani A, Sellami M, Bettahar N (2012) J Therm Anal Calorim 107:955-962

13. Blower SK, Greaves C (1988) Acta Crystallogr Sect C: Cryst Struct Commun 44:587-589

14. Schlesinger M, Schulze S, Hietschold M, Mehring M (2013) Dalton Trans 42:1047-1056

15. Shuk P, Wiemhofer HD, Guth U, Gopel W, Greenblatt M (1996) Solid State Ionics 89:179-196

16. Brezesinski K, Ostermann R, Hartmann P, Perlich J, Brezesinski T (2010) Chem Mater 22:3079-3085

17. Wang HW, Hu ZA, Chang YQ, Chen YL, Lei ZQ, Zhang ZY, Yang YY (2010) Electrochim Acta 55:8974-8980

18. Xie D, Su Q, Zhang J, Du G, Xu B (2014) J Mater Sci 49:218-224

19. Staudenmaier L (1898) Ber Dtsch Chem Ges 31:1481-1487

20. Guo CF, Zhang J, Tian Y, Liu Q (2012) ACS Nano 6:8746-8752

21. Lee DW, De Los Santos VL, Seo JW, Leon Felix L, Bustamante DA, Cole JM, Barnes CHW (2010) J Phys Chem B 114:5723-5728

22. Madhusudan P, Yu J, Wang W, Cheng B, Liu G (2012) Dalton Trans 41:14345-14353

23. Ciszewski M, Mianowski A (2013) Chemik 67:267-274

24. Stoller MD, Ruoff RS (2010) Energy Environ Sci 3:1294-1301

25. Hickling A (1949) Q Rev Chem Soc 3:95-125

26. Yang X, Lian X, Liu S, Wang G, Jiang C, Tian J, Chen J, Wang R (2013) J Phys D Appl Phys 46:035103

27. Gund GS, Dubal DP, Patil BH, Shinde SS, Lokhande CD (2013) Electrochim Acta 92:205-215

28. Chen Y, Zhang X, Zhang D, Yu P, Ma Y (2011) Carbon 49:573-580

29. Gilje S, Han S, Wang M, Wang KL, Kaner RB (2007) Nano Lett 7: 3394-3398

30. Gómez-Navarro C, Weitz RT, Bittner AM, Scolari M, Mews A, Burghard M, Kern K (2007) Nano Lett 7:3499-3503 